\title{
De Pegamo et Lambergare
}

\section{(nuga translatoria a Matthaeo Hriberšek Latine reddita versibusque originalibus pacta) ${ }^{1}$}

Tam béli Dunej mi stojí, Na Duneju kaj se godí, Me dobro poslušajte vi.

Je v' srédi mesta trática,

$5 \quad$ Na trati raste lípica, Dunej hladí nje sénčica. Pod sénco miza rúmena, Okoli mize stoli pa, Sedí na stolih góspoda.

10 Méd nimi cesar govorí: »Po moji misli se mi zdi, Kraléstvu našmu glihe ni.«

Perdirja Pégam in dričí, Ošabno tako govorí:

15 "So prazni vaš pogóvori!« Naprej še Pégam govorí: "Kar pravim vam, gospodji vi,« - Cesarja vun tud ne spustí "Imajo velk gospóstivó,

Katír bi skusil se z' meno.«

Vienna alba hic mi stat et quid Viennae nunc fiat nunc unusquisque audiat.

In urbe pratum media, in prato crescit tilia

Viennae dans umbracula. In umbra mensa rubea et circa sunt sedilia, sedet aristocratia.

Hos Caesar allocutus est: "Hoc visum mihi certe est: par regno nostro nullum est."

Accurrit Pegamus furens superbe eis sic loquens: "Voces inanes vir reddens! « Et addit Pegamus dicens: »Vos alloquor, primorum flos, « - nec Caesari dat exodos "regimen vobis magnum est; sed nullus vobis nunc subest vir fortis, mihi qui par est."

1 Fons: Štrekelj, Karol: Slovenske narodne pesmi. Iz tiskanih in pisanih virov zbral in vredil dr. Karol Štrekelj. Zvezek I. Izdala in založila Slovenska Matica. Natisnila tiskarnica Rudolfa Milica, V Ljubljani 1895-1898, str. 34-38 (Lambergar in Pegam. (Gorenjska.) a. Vodnikova redakcija iz 1. 1807.) 
Odgovorí mu car tako:

»Kaj češ prašati me za to?

Ga jmam, de ti presédal bo!

$\mathrm{Na}$ krajnski zemli mi živi,

Kér se na Kamnu govorî,

Se nikdar tebe ne bojí.

Kristof Lambergar z' imenam,

Na síni skal' prebiva tam,

Te v’ pest želí dobíti sam.«

Prav Pégam: "Píšite mu list,

Domá pustí naj vse na stran,

Perdirja meni naj v’ bran!«

Mu reče cesar pisat list,

Človéka berzniga dobít,

De more kmal do njega prit.

Izgóvori komaj enkrat,

Se najde preci pobeč mlad,

Kír list ponese njemu rad.

Ponese v' lepo deželo,

Goráto kranjsko deželo,

Tje Kristofo Lambergarjó.

Zvečer je Dunej zapustíl,

Letí kob' nega zlod podil,

Je zjutra žé v Teržíču bil.

Gospóde tuki gor budi,

Pohlevno nje nagóvorí:

"Ké Kristoph Lambergar stojí?»

Pred njim se vsi perklánajo,

50 S njemu nič ne zlažejo,

Mu z’ perstam grad pokažejo.

Za kapo vtakne béli list,

Naprot perklone jim se nisk,

Gre hitro, ko nebéski blisk.

V’ lini stara mat' stojí,

Inu per sebi govorí,

De to pa že nič prida ni!

Do sina teče svojiga,

Do Kristofa Lambergarja,

60 De b’ lepó ga podúčila:

»Koniča maš, ko tíčico,

Zlato zoble všeníčico,

Pié sladko rebúlico.

Stojí per jaslih sédem lét,

Na sonce mi nikol ne gré,

Nu vidil ni še bélga dné."

Tako še mati rekla je:

"O kaj ti pravim, Kristofé,

$\mathrm{Na}$ te rečí poslušaj me!

Premágal bodeš ti obá

Li glej, da te ne zapelá.

Ak bodeš videl tri glavé,

Dve krajne njemu pust obé,

Et Caesaris responsio:

"Quid haec interrogatio?

Est mihi - tibi taedio

erit; in Carnis residet,

quo Lapis arx nomen habet, est vir, qui numquam te timet. Christophi Lambergar sonat nomen, in rupe habitat, vult: 'Res ad manus veniat!'" At Pegamus: "Da litteras: 'Relinquas res domesticas et contra virum venias!" "

Caesar iubet, ei scribant ut litteras, inveniant ut celerem, qui mox virum assequatur; et vix dictum, apparet iuvenis puer, viro fert eas gaudenter. In pulchram fert eas terram, montosam Carnioliam, ad prolem Lambergariam. Viennam reliquit sero, ut actus a diabolo est mane in Foriculo. Hic nobiles vir expergit et mite eis haec dicit: "Christophus Lambergar vivit ubi? «Iuvenem adorant omnes, mentita nulla dant et arcem digito monstrant. Galero chartam inserit, adorans ad terram vergit et instar fulminis abit.

Apud fenestram mater stat et apud se sic murmurat: "Quam res se male habeat!" Ad prolem suam properat, ad Lambergarem Christophum, ut verbum ei det doctum: "Ut avem tu habes equum, qui flavum triticum vorat, rebulam suavem is potat. Septennis praesepi adstat, in solem equus numquam it nec claram lucem iam vidit." Haec mater ei iam dixit: „O, Christophe, quas dico has res tibi nunc, me audias! Habet diabolos duos

hic Pegamus, vinces ambos, at cave hos malos dolos. Extrema capita linquas, si tria forsan videas, et medium percutias." 
Podá se v' svitlo kamrico, $\mathrm{Na}$ glavo déne kápico, Perpaše sebi sáblico. Zaséde kónča berzdiga, Rokó pa materi molí: "Mat' moja, zdrav' ostante vi! « Mi zdaj pa z' konjam zadričí, Ko stréla hitro mi leti, In se popréd ne vstanoví: Po Duneju mi dirja v’ skók, So per kosilu vsi okróg, Pegamu pade žlica z’ rók.

Mu Pegam tako govorí: »Naj preveč teb' se ne mudí, De glave bi ne zgubil ti! Al očeš kaj počákati, Al češ se precej máhati Nu tvojo glavo vágati? « Je Kristof tako govoril:

95 »Ne bom se dolgo jez mudíl, Na Kranjskim sim še včéra bil.«

Ga praša Pegam spét takó: "Kej pa se bo godílo tó? Al tu na terg' širokimo? «

100 Mu pravi Lambergar takó: »Na polju, de vsi vidio, Za najo čast se bíeva." Nasproti zdaj zadírjata, Za všesmi se oprášneta,

105 Si nič ne sturta húdiga.

Takó pa Pegam govorí: „Premočniga mi še bilo ni, Te Kristofe to kaj skerbí? Al konjič tvoj bo žáloval, 110 Po polu bode razgatal, Kí gospodarja bo iskal." $\mathrm{Pa}$ Kristof tako govori: "Za drúgiga pa meni ni, Ko to, kar tebe mal' skerbí:

115 Za tojo žídano gospó, Kí tako mlada vdóva bo; Ne véš, de men dopadla bo?«

Se drugo Pegam zaletí, Se Kristofu pokáže kri, 120 Mu vonder sile ne sturí.
Cubiculum clarum intrat, galerum capiti aptat, coxis ensem accomodat. Equum velocem ascendit et matri manum porrigit: "Genetrix nostra salva sit!" Equo admisso utitur fulmineusque vehitur non prius vir subsistitur; Viennam cursu percurrit vulgus hic cenam habuit, Pegamo applar excidit.

Pegamus edit voces has: »Nunc properare caveas, ne tuo capite luas! Vis paulum se reficere aut statim vis confligere in ultimo discrimine?" At Christophus responsui: "Paulum morari statui; in Carnis heri iam fui.«

Secundum poscit Pegamus: "Sed ubi confligabimus? In foro lato sit locus?" Sic dicit ei Christophus: "Ad laudem nitimur campo nunc omnibus spectaculo." Rursusque ambo procurrunt, sed aures solum perstringunt, nil mali tamen faciunt.

Sic Pegamus ei dixit: "Non erat, qui me vicerit, hic angor, Christophe, an sit? Sed equus tuus gemiscet, per campum hinnitum edet, cum suum dominum quaeret." Et Christophus responsum dat: "Res nulla me sollicitat quam quae et paulum te turbat: tua uxor venustula, quae erit nova vidua; nescis, quam erit mi grata?

Secundo Pegamus ruit, Christopho sanguis effluit, attamen male nil facit. 
Ko v tretje vkúp’ zadirjata, Takrat se dobro póčita, Za vselej boj razlóčita. Je méril Kristof srédniga,

125 Na stran je pustil krajniga, Udári ravno srédniga.

Je njemu pravo glavo vzél, Pa hitro njo na jévca vjel, Ves Dunej je čez to vesél.

130 Dričí na béli Dunej z' njó, Z' junaka Pégama glavó, Jo kaže Dunejcam lepó.

Mu reče tako svitli car: »Junák, ti moški Lambergar,

135 Kaj češ iméti za tvoj dar? « Pa Lambergar odgovorí: »Na Kranjskim imam tri gradí, De b’ moji, prosim, lastni bli!«

Pa cesar tako govorí:

140 »Kar češ imét, nej se zgodí, Kar dolgo li tvoj rod živí!«
Cum tertio nunc iruunt, tunc bene manus conserunt, ad acta ferro decernunt. Christophus tendit medium, non ei curae extremum, percutit ipsum medium. Verum rapit caput ferro, capit cito manubrio, Viennae magno gaudio. Viennam albam properat et caput Pegami vibrat, Viennae incolis monstrat.

Illustris dicit sic Caesar: "Vir fortis, noster Lambergar, qua re donatus esse vis?" At Lambergar respondet his: "In Carnis arces tres mi stant, te oro, ut meae fiant!"

Et hoc decretum Caesar dat: "Quae vis habere, nunc fiat et longe tua gens vivat!"

(Viennae mense Octobri AD MMXVI) 